\title{
Timing the Application of Beneficial Nematodes to Mole Cricket Activity on Pasture to Optimize Control ${ }^{1}$
}

\author{
M.B. Adjei, G.C. Smart, Jr., J.H. Frank and N.C. Leppla ${ }^{2}$
}

\section{Ss Nematodes}

Steinernema scapterisci (Ss), an

entomopathogenic nematode, has been developed by the Institute of Food and Agricultural Sciences (IFAS) scientists specifically to provide permanent biocontrol of mole crickets on pastures and turfgrasses. The nematode is being mass-produced, and is commercially available under the trade name Nematac $S^{\circledR}$ by MicroBio, a subsidiary of Becker Underwood, Inc., Ames Iowa.

Nematac S contains the infective juveniles (IJs) which are the only free-living stage of Ss nematodes. The IJs in the Nematac S product do not feed but may live for months on stored reserves if kept cool $\left(40^{\circ} \mathrm{F}\right)$. Once applied on a pasture or turfgrass, the sole function of the IJs is to search for an adult or pre-adult mole cricket, invade it, and initiate infection. The reproductive stage of Ss nematodes normally takes place inside a mole cricket cadaver. This factsheet provides guidance for optimizing a match between those two entities.
The IJs do not move far in the soil but depend on mole crickets to move to them. The IJs then attach to a mole cricket, enter it through its mouth or spiracles, and initiate an infection. Active dispersal by the IJs in the soil may be measured in inches. By comparison, passive dispersal of the nematodes by mole crickets may be measured in miles. Additionally, the length of time that Ss juveniles survive in soil after application and without finding a mole cricket is days or weeks depending on soil temperature, type, and moisture, and natural enemies. Survival is better in sandy or sandy-loam soils, adequate moisture, and temperatures between 60 and $75^{\circ} \mathrm{F}$ than in clay soils, excessive moisture, and higher or lower temperatures. Numerous organisms in the soil prey on the IJs (eg mites, collembola, enchytraeids, fungi and other nematodes). Therefore, large numbers of IJs are normally applied ( 1 billion/A), and they must find and infect a mole cricket in the shortest possible time after application for biocontrol to occur.

1. This document is ENY-663 (IN413), one of a series of the Entomology and Nematology Department, Florida Cooperative Extension Service, Institute of Food and Agricultural Sciences, University of Florida. Published February 2002. Revised: August 2006. Visit the EDIS Web site at http://edis.ifas.ufl.edu. 2. M.B. Adjei $\dagger$, assistant professor, Range Cattle Research and Education Center, Ona, G.C. Smart, Jr., professor, J.H. Frank, professor and N.C. Leppla, professor, Entomology and Nematology Department, Florida Cooperative Extension Service, Institute of Food and Agricultural Sciences, University of Florida, Gainesville, 32611.

$\dagger$ Died 15 August 2006 in a tragic car crash.

The Institute of Food and Agricultural Sciences (IFAS) is an Equal Opportunity Institution authorized to provide research, educational information and other services only to individuals and institutions that function with non-discrimination with respect to race, creed, color, religion, age, disability, sex, sexual orientation, marital status, national origin, political opinions or affiliations. U.S. Department of Agriculture, Cooperative Extension Service, University of Florida, IFAS, Florida A. \& M. University Cooperative Extension Program, and Boards of County Commissioners Cooperating. Larry Arrington, Dean 


\section{Mole Cricket Activity}

Surface activity of mole crickets in a pasture during the year is best described by an bell curve (Figure 1). Tawny and southern mole crickets usually overwinter as adults in deep burrow systems. Following their mating flight in early spring (mid-February to April), when temperatures become warm, many adults relocate and lay clutches of eggs in underground chambers. By early June, most adult mole crickets die just as the hatchlings (tiny nymphs) of the new generation begin feeding on pasture. These hatchlings are largely nomadic because they have no permanent 'home' burrows. They tend to seek escape above ground and move in groups especially following heavy rainfall (>1 inch). Adults may retreat into deep burrows rather than coming to the surface. As a result, pitfall traps permanently set in pastures usually record higher numbers of nymphs than adults throughout the year.

The peak nymph activity between June and September may be used to assess the magnitude of mole cricket infestation on a site, but it is not the best time for Ss nematode application. By October, the nymphs that hatched in June have developed into large nymphs (juveniles) and young adults with wings. As a result, surface activity decreases and subsurface activity (tunneling) increases. A considerable amount of damage to sod occurs during feeding and tunneling in the fall.

\section{Timing of Application}

The seasonal pattern of mole cricket activity in pasture is critical for timing the application of Ss nematodes and for an evaluation of the biocontrol outcome. Nematodes are more effective on large juveniles and adults, which have larger body openings, than on nymphs. Two times that are ideal for Ss nematode application to pastures in Florida are February to April (March-April in northern Florida), and September to November when a high percentage of adult mole crickets is present (Figure 1).

Nematode application during these periods should be timed for early mornings or evenings and following rainfall or irrigation to ensure cool, moist conditions necessary for nematode survival. Upon successful entry and infection in mole crickets, the nematodes will reproduce in the mole cricket cadaver and recycle back into the soil to allow for long-term mole cricket control.
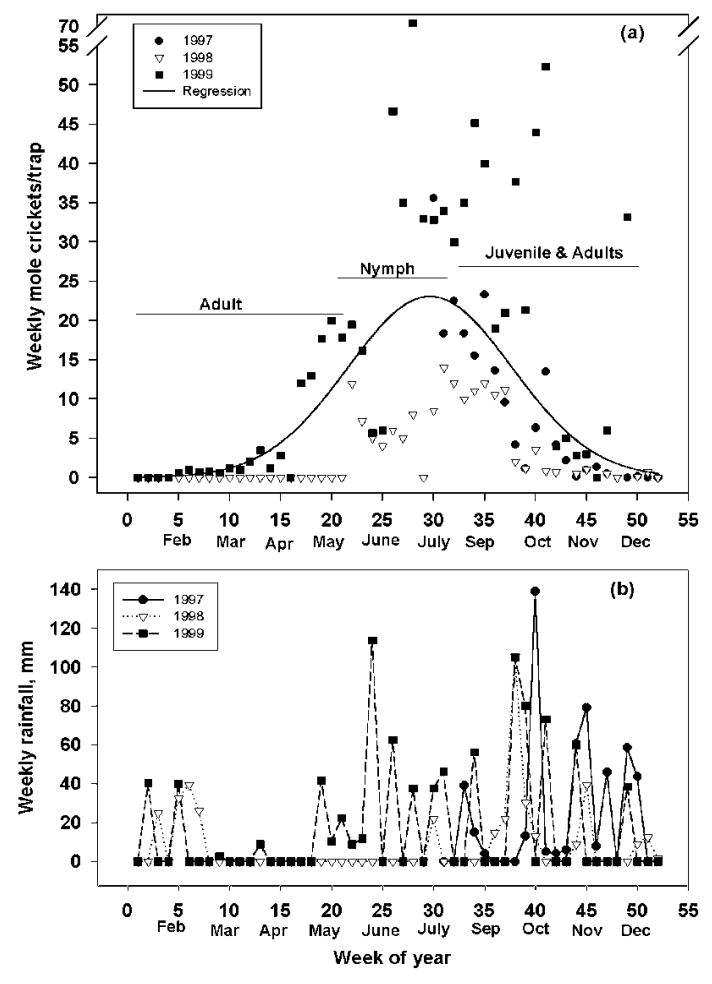

Figure 1. Seasonal surface activity of pest mole crickets on pasture (a) and its relationship with summer rainfall (b).

\section{Recommendations to Optimize Guest-Host Match on Pastures:}

1. Purchase fresh nematodes (Nematac $S$ ) within a few weeks before planned application (even better to have them arrive as close to application time as possible).

2. Store nematodes in a refrigerator at about $40^{\circ} \mathrm{F}$ $\left(4-6^{\circ} \mathrm{C}\right)$.

3. Transport nematodes to the field in a cooler with ice or in an air-conditioned vehicle. Use a towel or other barrier to prevent direct contact with the ice.

4. Time application for early mornings or evenings in February-April or September-November.

\section{Apply nematodes to moist soil.}


6. Use a machine with injector tines or a modified slit-seeder that can place the IJs in suspension 1 inch below the soil surface and close the slit with press wheels. If soil is very moist and plant cover is not too dense, a sprayer rig with filters removed can also be used (Check pump and nozzle)

7. Mix nematodes directly into a tank partly filled with fresh, clean water with the agitator running, and then bring volume up to 100 gallons.

Calibrate to apply enough suspension to obtain 1 billion nematodes in 100 gallons of water to an acre.

8. Apply the nematode suspension in strips, immediately after mixing, while maintaining constant agitation, to one-eighth (Figure 2) of the pasture to be treated.

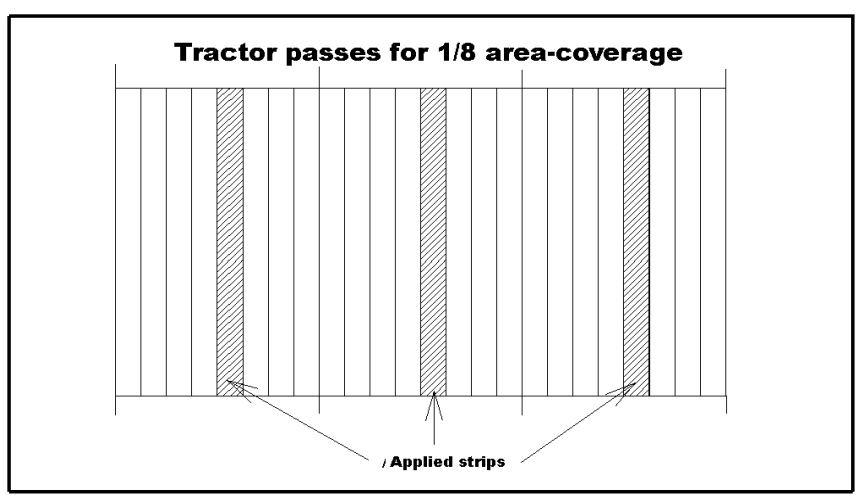

Figure 2. Mark out sprayer widths on field and turn on the sprayer every eighth pass to achieve $1 / 8$ area-coverage. 